\title{
Experimental Evaluation of an Internally Passively Pressurized Circulation Control Propeller
}

\author{
Jonathan Kweder, ${ }^{1}$ Cale H. Zeune, ${ }^{2}$ Jon Geiger, ${ }^{3}$ Andrew D. Lowery, ${ }^{1}$ and James E. Smith ${ }^{1}$ \\ ${ }^{1}$ Mechanical and Aerospace Engineering Department, 395 Evansdale Drive, West Virginia University, \\ Morgantown, WV 26506, USA \\ ${ }^{2}$ Low-Speed Aerodynamics Branch, Air Force Research Laboratory, Wright-Patterson Air Force Base, \\ Fairborn, $\mathrm{OH} 45433$, USA \\ ${ }^{3}$ Jacobs Engineering, Air Force Research Laboratory, Wright-Patterson Air Force Base, Fairborn, OH 45433, USA \\ Correspondence should be addressed to James E. Smith; james.smith@mail.wvu.edu
}

Received 26 April 2013; Revised 15 November 2013; Accepted 19 November 2013; Published 3 February 2014

Academic Editor: Ujjwal K. Saha

Copyright (C) 2014 Jonathan Kweder et al. This is an open access article distributed under the Creative Commons Attribution License, which permits unrestricted use, distribution, and reproduction in any medium, provided the original work is properly cited.

\begin{abstract}
The purpose of circulation control for fixed wing aircrafts is to increase the lifting force when large lifting forces and/or slow speeds are required, such as at takeoff and landing. Wing flaps and slats are used on almost all fixed-wing aircraft. While effective in increasing lift, they do so with penalty of increasing drag, weight, and control complexity. The goal of this research was to find an alternative way of pumping pressurized air to the trailing edge slot on a UAV propeller. This design called for rerouting stagnation pressure from the frontal propeller area through the inside of the propeller blades to ejection slots on the trailing edge. This allows for the forward velocity of the aircraft to drive the pressurization of the circulation control plenum passively, without additional hardware. For this study, a Clark-Y airfoil section propeller with an overall diameter of 0.609 meters was designed and tested. The comparison of the augmented to unaugmented propeller showed a 5.12 percent increase in efficiency, which is shown to act over the entire range of flight envelopes of the aircraft and is shown to be particularly beneficial at advance ratios above 0.30 , normal operating conditions of propeller-driven UAVs.
\end{abstract}

\section{Introduction}

Circulation control (CC) is a lift augmentation methodology that can be used in a variety of fluid dynamic systems, such as on the wing of an aircraft. Applications of this technology have been in the research and development phase since the 1960 s with the primary emphasis on fixed-wing aircraft where the initial implementations of this technology were referred to as "blown flaps." Circulation control increases the near surface velocity of airflow over a rounded surface of an object, typically a slightly modified airfoil. This is primarily achieved though the addition of a jet of air to a specially designed aircraft wing using a series of blowing slots that eject pressurized high velocity (faster than the free-stream velocity) jets of air over the trailing edge and/or leading edge [1-5].

The most prevalent design for a circulation controlled wing has a rounded trailing edge and ejects the air tangential to the surface, inducing the Coandă Effect. The Coandă Effect is typically characterized by a boundary layer jet that remains attached to the wing surface longer than a conventional wing and thus increases the virtual length, camber, and the angle-of-attack of the airfoil by entraining the free-stream air near the jet $[6,7]$. The jet blowing over the rounded trailing edge increases the circulation of the free-stream around the airfoil, increasing the aerodynamic forces. As the circulation control airflow entrains free-stream air, the interaction between the object and the surrounding fluid alters the pressure distribution along the surface of the airfoil, another indication of the altered and normally enhanced forces experienced by the object.

The principal motivation for the use of circulation control has been to increase the lifting force when large lifting forces, particularly at slow speeds, are beneficial, such as at takeoff and landing $[2,6,8,9]$. On current fixed-wing aircraft, wing 
flaps and leading edge slats are used during landing and on takeoff to increase lift generation [10-21]. The benefit of the circulation control wing is that no additional skin friction drag is created by the increased surface area produced by the movement of conventional surfaces into the airflow around the wing. This results in an increased lift coefficient. However, as with any lifting surface, the use of circulation control increases the induced drag of the airfoil in proportion to the square of the lift coefficient [22]. Additionally, these active circulation control systems require energy to pump the fluid, along with the additional hardware, weight, and system complexity which can reduce the effectiveness achieved by the additional lift.

A further consideration of circulation control to rotorcraft applications comes in managing the power needed to supply the augmented airflow. An active circulation control system uses an internal pumping system which can draw power from the original aircraft power plant or from another additional power source, such as a compressor, to pressurize the air plenums in order to implement circulation control on the aerodynamic body. In the past, for some of these applications, the additional weight and cost of components far surpassed the benefits derived from the use of circulation control. While new materials and control strategies have made available a great variety of applications using active circulation control for some simpler systems can still be problematic.

According to a report published by National Aeronautics and Space Administration (NASA), in conjunction with Bionetics Corporation in June 1981, early research was completed examining the effect that circulation control had on applications to propellers [23]. This report specifically found that the overall system provided "greater than 7 percent reduction in fuel usage at cruise." This result was found on a system applied to a "puller-type" 1.83 meter diameter propeller, with an added external pumping system (actively pressurized circulation control plenum). This added pumping system siphons power from the engine and adds additional weight to the overall aircraft, rendering the tradeoffs of adding the system to the aircraft uneconomical. However, absent the weight and complexity of the additional pressurization system, the benefits of circulation control have been clearly demonstrated. Thus, the object of this study is the development of a passive pressurization system for potential use in future high efficiency propeller applications [23].

There are numerous conventional aircraft that use propellers ranging from pilot controlled sport and passenger aircraft to a growing number of unmanned and remote piloted vehicles. This newest area of unmanned and autonomous aircraft, with their restrictive flight regime requirements, has forced designers to consider a variety of flight envelope enhancements in hopes of squeezing a few more percentage points, if not parts of a percentage point, out of the performance of these vehicles. Though potentially beneficial, the application of an active circulation control to a UAV's propeller would likely create technical difficulties by adding weight and system complexity thus reducing the effectiveness of the craft. A passive system in which air can be supplied to a strategically placed circulation control blowing slot could be used to enhance the performance of these aircraft. It is envisioned that the design of a passive circulation control system on the propeller would not require this extra system weight and complexity and would create a self-contained air supply of its own.

Preliminary research has been done at WVU with respect to the feasibility of adding a passively pressurized circulation control slot to a propeller body, for implementation to already existing UAV aircraft [24]. This previous work showed that the use of a rounded trailing edge and circulation control plenum/ejection slot at specifically designed and located areas on a propeller blade could potentially provide a single digit performance increase in thrust of the propeller, thus increasing the overall efficiency and fuel economy of the aircraft.

This passive system can take advantage of the pressure differential upstream and downstream of the propeller plane, forward air velocity, and centripetal acceleration of the propeller to pressurize the internal plenum of the circulation control system. In doing so, no additional power source will be necessary to augment the propeller of the aircraft.

\section{Research and Development Objectives}

The overall goal of this particular research program was to use a specifically redesigned propeller to study the effect that the passive capture and use of stagnation pressure from the frontal area of the propeller plane could have on thrust augmentation of an aircraft. This was done in an experimental environment to show differences in thrust and required torque values of a CC modified propeller as compared to the conventional propeller.

\section{Blade and Circulation Control Plenum Design}

The inside slot geometry and propeller blade plenum proved to be a difficult portion of the design of this particular propeller. The unaugmented propeller chosen for this experimentation was purchased as an off-the-shelf replacement part and was 0.61 meters in diameter and at its largest point was only 0.001 meters in thickness. After extensive background research into the use of circulation control on other airfoils, wings, and aerodynamic bodies it was found that the most important parameters for circulation control to be effective were the exit-slot-height-to-trailing edge-radius-ratio $\left(h_{j} / r\right)$, trailing-edge-radius-to-chord ratio $(r / c)$, and exitslot-height-to-chord ratio $\left(h_{j} / r\right)$. The most useful of these parameters [4] were plotted and can be found in Figure 1. The ratios of this particular propeller experiment fall just within the bounds of the region of effectiveness, with the values for this particular model being $0.04 \mathrm{r} / c, 0.002 \mathrm{~h}_{j} / c$, and $0.05 h_{j} / r$, shown in Figure 1, highlighted with a yellow circle, just at the upper most bound of the region of most effective Coandă operation.

In order to model the geometry of the propeller accurately in an engineering software package, to be able to manipulate the dimensions, and to provide a circulation control plenum inside the propeller blades, the first step was to scan the unaugmented model with a three-dimensional camera. The 


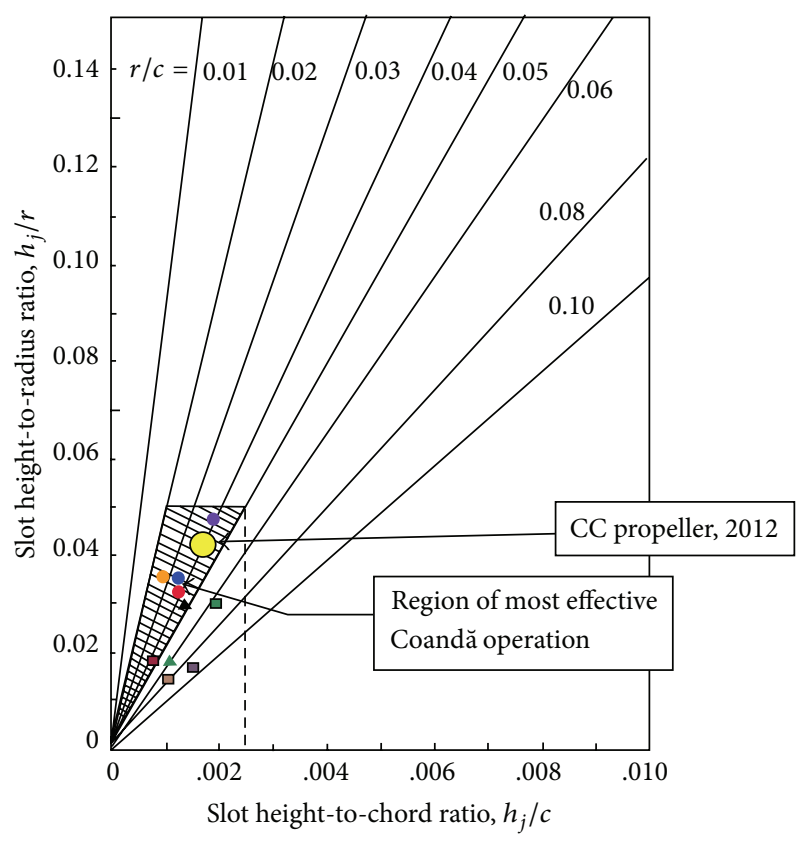

- Kind/Maull (1968): 20\% t/c CC-ellipse

- Williams (1969): $20 \% t / c$ CC-ellipse

- Englar (1971): 15\% t/c CC-ellipse

- Englar/Williams (1971): 20\% $t / c$ CC-ellipse

- Ottensoser (1974): $20 \% t / c$ CC-ellipse

- Englar (1979): NACA 64A008.4/CCW

- Wood (1981): $20 \% t / c$ CC-ellipse

- Novak, et.al. (1987): $20 \% t / c$ CC-ellipse

- Franke/Harvell (1994): $20 \% t / c ; 1.5 \%$ camber CC-ellipse

- WVU model B (1970): 20\% $t / c$; 5\% camber CC-ellipse

FIGURE 1: Region of most effective circulation control geomerty [3, $4,10,11,15,25-32]$.

scan was done with a Konica Minolta Range 7 with some smoothing and after processing done inside the Konica Minolta proprietary software. When the resulting model was oriented and surfaced appropriately, as a solid, with no camera artifacts, it was exported as a stereo lithography file and then imported into Pro-ENGINEER. The threedimensional modeling software aided in the ability to model the circulation control plenum to the inside of the propeller blades without the need to waste time and resources on building several different models. This software allowed for fast variation of slot geometry, and coupled with a flow visualization software the models were checked for flow criteria and a final dimension was chosen based on the flow characteristics predicted at the circulation control exit.

Through contact with the propeller manufacturer, it was found that the unaugmented propeller had a Clark-Y crosssectional area, with the data points being fit to a unity chord length. The new augmented propeller also had a similar crosssectional shape, with the addition of the added circulation control plenum. The size of this type of airfoil illustrates the amount of space within the propeller blades that the augmented propeller needed to be designed around.

In order to drive the airflow through the propeller blades to the exit slot, the choke area of the circulation control

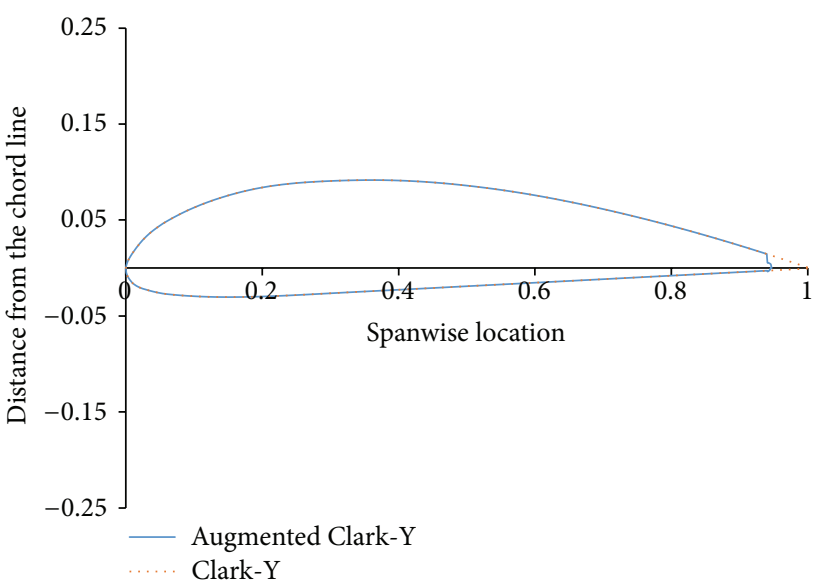

FIGURE 2: Rounded trailing edge modification for Clark-Y airfoil.

system needed to be the cross section of the exit slot. The height of this slot also depended on the accuracy of the threedimensional printer that would eventually make the prototype. The rapid prototyping machine employed to make this part was the Fortus $900 \mathrm{mc}$. Taking the three-dimensional model from the computer software and modeling the propeller layer-by-layer ( 0.127 millimeters in accuracy) two prototypes were made, one constructed of a polycarbonate (PC) and the second out of ULTEM 9085 plastic. The latter is a material conceived by the rapid prototyping company and was tested to withstand bending better than the PC type materials as well as having the ability to be printed in smaller layers. The ULTEM 9085 material was considered the strongest material available for the printer both in shear strength and in flexure resistance providing the best available choice for experimentation at high rotational and thrust loads. Figure 2 shows a comparison of the original Clark-Y cross-sectional geometry plotted over the CC augmented chordwise geometry. Because of the addition of a rounded trailing edge and CC ejection slot, the overall chord length of the airfoil was reduced to accommodate the radius of the trailing edge.

The internal plenum of the propeller was designed in the Pro-ENGINEER software package using the Konica Minolta scanned files as a starting point. The propeller scans were all merged together and assembled as a solid model file. This model was then manipulated, using variable-section sweeps and splines to create an internal geometry to allow the pressurization air to flow from the front plane of the propeller to the trailing edge ejection slot. The geometry of the plenum had to be varied throughout the radial locations in order to allow for the twist of the blade and still keep the plenum relatively constant distance away from the wall's surface. This was done in order to prevent any unusual bending stresses while the blade was under load while testing. Figure 3 shows the radial locations for the internal plenum slot geometry changes. In order to keep the geometry changes as uniform as possible and to avoid any abrupt cross sectional changes that would impact the airflow characteristics, there were four different sections designed (Sections A through D). 


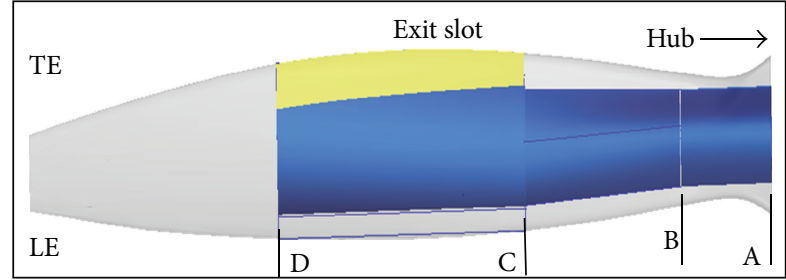

Figure 3: Radial locations of section sweeps of pressurization plenum.

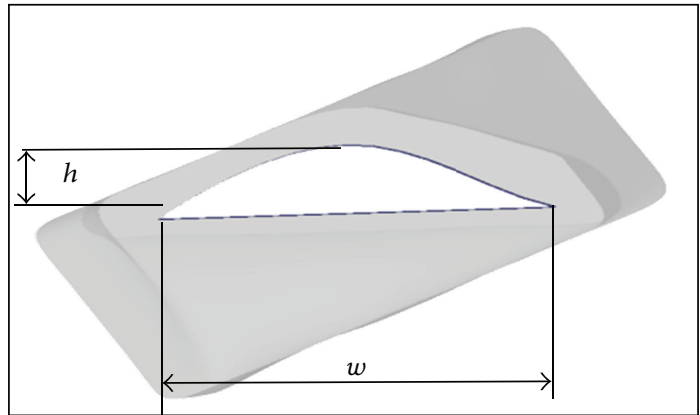

FIgURE 4: Height $(h)$ and width $(w)$ of the CC pressurization plenum.

TABLE 1: Blade plenum reference geometries.

\begin{tabular}{lcccc}
\hline & A & B & C & D \\
\hline Width $(\mathrm{m})$ & 0.026 & 0.026 & 0.030 & 0.028 \\
Height $(\mathrm{m})$ & 0.0063 & 0.0063 & 0.0043 & 0.0041 \\
\hline Segment & A-B & B-C & C-D & A-D \\
\hline Length (m) & 0.034 & 0.061 & 0.096 & 0.19 \\
\hline
\end{tabular}

In Figure 4, the root-to-tip geometry of the plenum is shown with regard to the overall dimensions of width and height. The generic shape of the section sweep did not change over the radial locations; however, as shown in Table 1, the overall width and height dimensions changed as a function of radial location toward the tip of the propeller. From section A to section $\mathrm{B}$ the dimensions are constant, providing a channel for the pressurization air.

Then, the dimensions increase in the chord direction (the width of the slot) to account for the change in blade twist, forming a nozzle type of flow condition for the air to flow through. Finally between Station C and Station D, the plenum begins to reduce in size again, both in height and width dimensions, accounting for the ejection slot which spans the trailing edge of the entire 0.088 meter segment. At Station D, the plenum ends with the ejection slot, giving way to a solid blade planform as in the original propeller.

The sensitivity analysis done on a computer model of the circulation control propeller showed that the middle third of the propeller blade provides the most useful enhancement to the output lift/thrust of the propeller. Therefore, in order to minimize the effect drag when adding a circulation control slot and rounded trailing edge to the propeller, only the middle third of the propeller was retrofitted with CC ejection slots. In Figure 5, the exit slot of one propeller blade can be seen as well as the plenum cross section throughout the length of the blade. To enhance the strength of the propeller as best as possible, the circulation control plenum was not extended past the ejection slot providing a solid blade cross section along the outer third of each blade.

\section{Experimental Apparatus}

While testing at the WPAFB/AFRL wind tunnel, several components were used which were considered the main components of the vertical wind tunnel. The propeller was mounted to an adjustable sting along with the electric motor, used to drive the model. The sting was then able to be positioned in the flow of the tunnel according to several different angles of attack to the free-stream as well as be positioned directly over the centerline of the tunnel for most reliable test results. In Figure 6, the propeller and motor are positioned on the end of the wind tunnel mount, with a three-axis force balance directly behind the motor. The maximum force able to be recorded through the force balance was 88.9 Newtons, with a manufacturer specified error value of 0.05 Newtons.

A Hall Effect sensor was used in the rear of the propeller hub to measure rotational speed, basically picking up a magnet signature every time it passed its field of view. Due to the simplicity of this apparatus, no error was taken into account for this particular measurement device. In Figure 7, the voltage regulation and signal generator are shown which were used to run the electric motor while testing was completed. The motor was connected to the 30 volt power source, which was digitally controlled to 0.1 volts, and the Hall Effect sensor and force balance were electrically driven by the 5 volt power source. The 5 volt source had an experimental error input of \pm 0.5 volts due to the analog dial used to set the output.

The wind tunnel itself was also characterized, with several different measurement devices and copared to produce an estimated error analysis for measuring the flow velocity of the tunnel while testing. In Figure 8, the data was gathered in relation to the tunnel fan rpm because the data acquisition software was already written to easily change fan speed. Among the instruments used were an anemometer mounted to the wall of the tunnel at all times to monitor the velocity during testing, a simple pitot probe, randomly placed throughout the tunnel radially, a separate wall mounted pitot probe (which acts as a backup to the anemometer), and a sting mounted pitot probe measuring data that the propeller would encounter. All the velocity profiles are shown in the data, as in Figure 8. The resulting error analysis showed only a 5 percent difference in all the measurement values, which was used as measurement error in the final data calculations.

\section{Experimental Testing Schedule}

To accurately test over the entire range of advance ratios for this model and to find corresponding efficiency ratios for the augmented propeller, this experimental study tested ranges of advance ratios between 0.3 and 1.1. The testing schedule used while experimenting in the WPAFB wind tunnel is shown in 


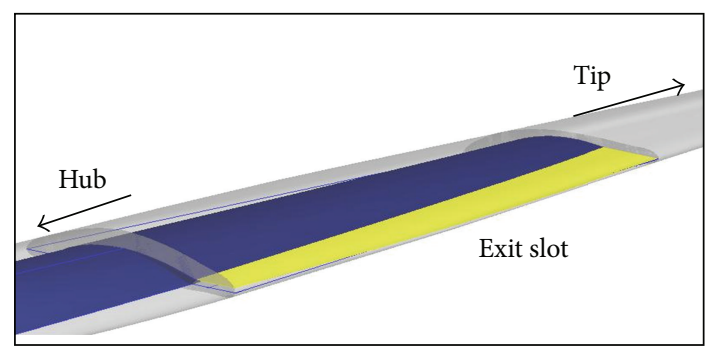

Figure 5: Exit slot and plenum of circulation controlled propeller blade.

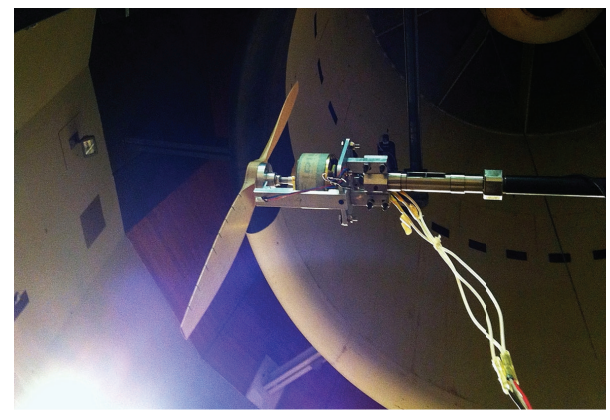

FIGURE 6: Wind tunnel apparatus.

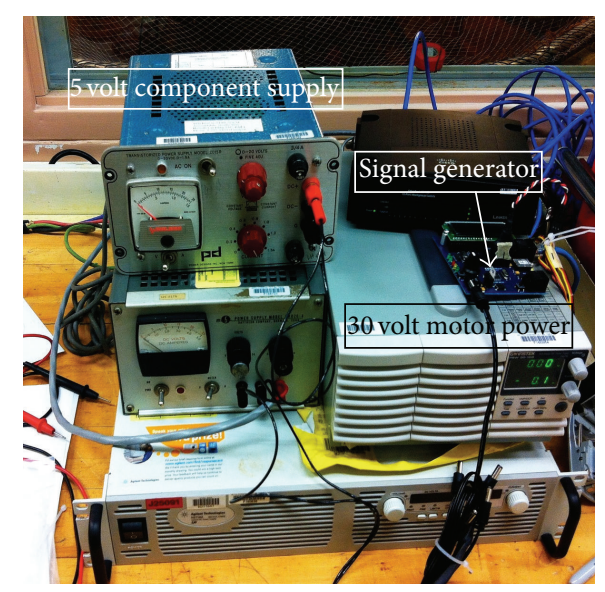

FIGURE 7: Experimental voltage regulation apparatus.

Table 2 and was conducted over a range of tunnel velocities including 4.47, 8.94, and 13.412 meters per second. The output data of this experiment gave values for the output thrust capabilities of the propeller as well as the input voltage needed to turn the propeller at a specific rotational speed. This input voltage converted to a power input could then be used to calculate the torque input needed from the motor.

The thrust was measured with the three-axis force balance system mounted in the tunnel, while the torque was calculated via measured input power and measured rotational speed. The data runs were sampled at a rate of 200 samples per second. Also present during testing were a series of anemometers and digital pitot probes which were used to monitor the velocity of the tunnel while in operation. This
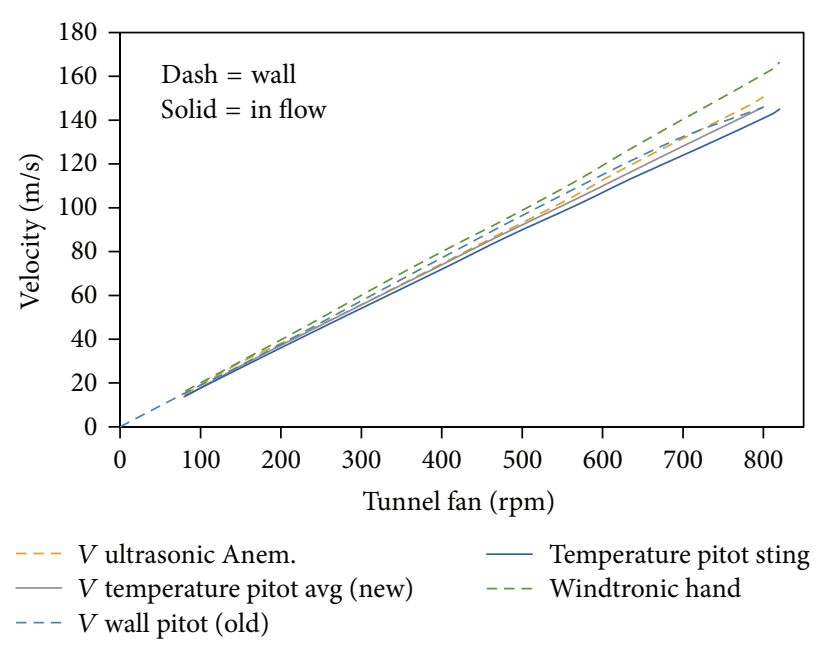

FIGURE 8: Velocity measurements from the wind tunnel.

TABLE 2: Advance ratio testing schedule at WPAFB/AFRL wind tunnel.

\section{Propeller}

Tunnel velocity $=10,20,30$ miles per hour

\begin{tabular}{lcc} 
Diameter $(\mathrm{m})$ & Rotational speed $(\mathrm{rpm})$ & Rotational speed $(\mathrm{rps})$ \\
\hline 0.60 & 0 & 0 \\
0.60 & 600 & 10 \\
0.60 & 1200 & 20 \\
0.60 & 1350 & 22.5 \\
0.60 & 1500 & 25 \\
0.60 & 1650 & 27.5 \\
0.60 & 1800 & 30 \\
0.60 & 1950 & 32.5 \\
0.60 & 2100 & 35 \\
0.60 & 2250 & 37.5 \\
0.60 & 2400 & 40 \\
0.60 & 2700 & 45 \\
0.60 & 3000 & 50 \\
0.60 & 3600 & 60 \\
0.60 & 3799.98 & 63.333 \\
\hline
\end{tabular}

data was uploaded to a spreadsheet to be used in the calculation of the final performance results.

\section{Experimental Results}

The first variable that was examined was the thrust comparison between the augmented and unaugmented propellers at static conditions. This gave a starting point for what kind of performance the propeller can be predicted to have while in operation. It is also necessary to have the static data on file as that is the industry standard on how to size the propeller according to what kind of payloads and flying characteristics are predicted. In Figure 9, the theoretical calculations for thrust of a propeller are given in relation to the actual tabulated values taken during experimentation in the wind 


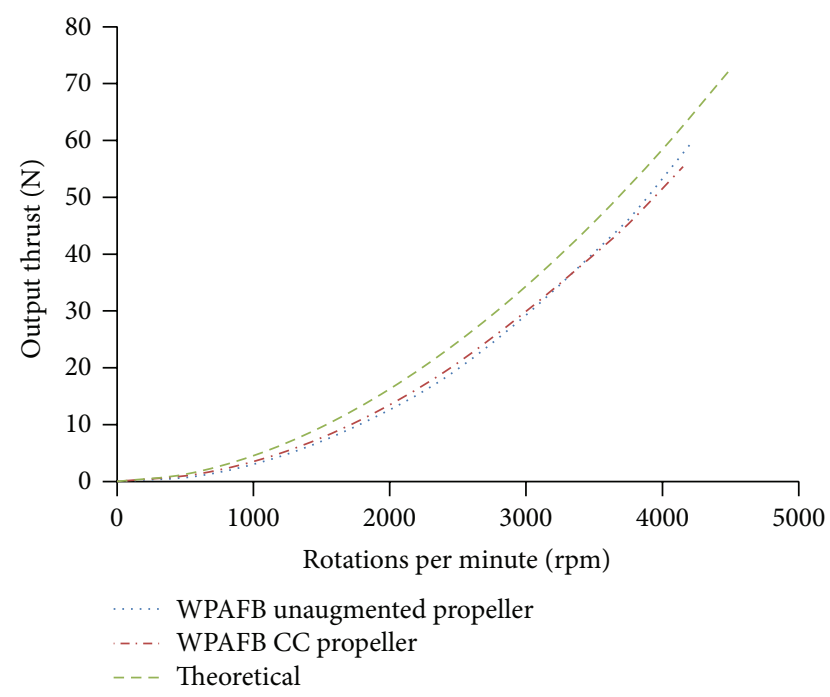

FIGURE 9: Theoretical static loading compared to experimental results.

tunnel. In this analysis, the trends of the data are shown to agree; however, the simplistic view of the theoretical static loading equations does not take into account boundary layer effects and slipstream offset for the end result. As a result, the theoretical calculation of static loading on a propeller is an overestimated result, which is offset with a standard error factor already included in the sizing convention.

When evaluating the augmented and unaugmented propellers with respect to the specific tunnel in which the experiments were conducted, the accuracy of the data collected was shown to be close to the theoretical calculations. Static propeller characterization allows for a manufacturer to use maximum allowable thrust settings to size a propeller to a specific need or application. These types of specifications are useful when choosing a motor or engine to mount with the propeller and aircraft. It is necessary to know the maximum capabilities of the propeller before sizing an ample power supply for the craft. As an example of this, the maximum output thrust for the original Zinger propeller [33], used as the baseline propeller for these tests, was approximately 60.0 Newtons. Consequently, the motor chosen to drive the experimental analyses as well as the mounting sting and force calibration apparatuses was sized according to this output force.

\section{Wind Tunnel Testing Analysis}

For the experimental runs, data for thrust force and input current were the main factors taken into account. These values were used to study the overall performance of the propeller in both aerodynamic performance (thrust and torque required) and overall efficiency (based on input and output relationships). Between the two propeller geometries and testing scenarios, the thrust forces are shown to be similarly linked. However, the experimental data for the amount of input current needed to turn the propeller is higher for the unaugmented propeller in comparison to the augmented case. This suggests that the overall lift of the propeller blades

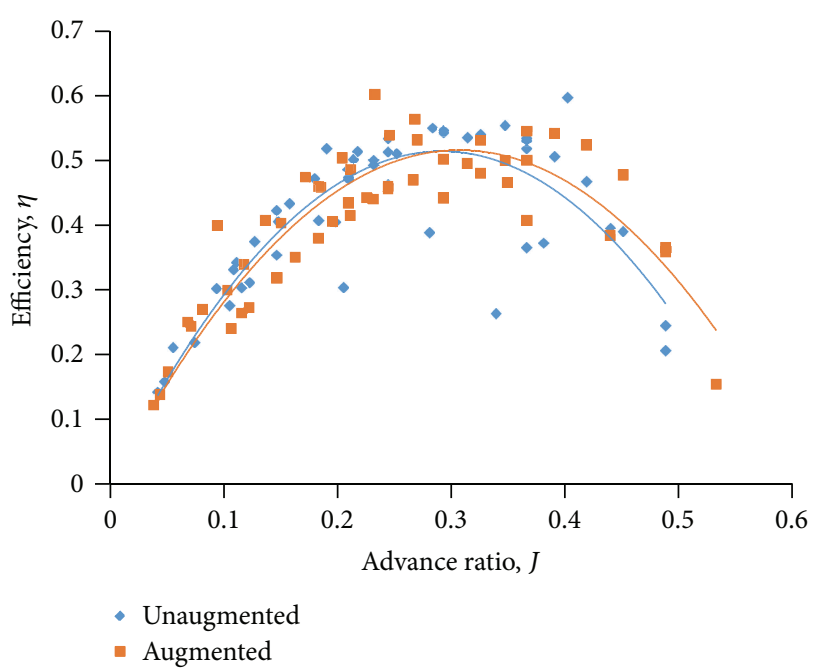

FIgURE 10: Propeller efficiency performance data.

has remained relatively constant between the two blade plan forms, and the drag values of the augmented propeller have been reduced with the pumping of the stagnation air for use in circulation control.

In Figure 10, the experimental efficiencies are shown for the unaugmented propeller as well as the augmented propeller. These plots show the output results of the trend studies of the two propellers over two different testing conditions and show conformity between the two. Because the propeller stopped producing thrust at an advance ratio of 0.60 , the results found were for what would be termed a "wind-milling propeller." This began the area of performance where the propeller no longer produces thrust power but began adding power back into the system.

In Figure 11, the measured thrust forces during experimentation are shown as nondimensional values $\left(C_{T}\right)$ with respect to the corresponding advance ratio of the propeller. The trends for both propellers show a second order fit decline in output thrust as advance ratio increases and show a net negative thrust output leading to power being taken from the free-stream velocity, much like a windmill or wind turbine type of effect. Experimental results show that the output thrust force of the augmented propeller is equal to or slightly more than the baseline unaugmented experimental propeller at all advance ratios. In specific tested sections between advance ratios of 0.15 and 0.25 , the two resulting thrust capabilities are very close to being equal, with the augmented propeller measured to be slightly higher, measuring as much as 5.0 percent more.

In Figure 12, the input current measured for each advance ratio of the propeller tests was converted into a power consumed by the motor in order to rotate the propeller to a certain rotational speed. The trend study shows that at low values of advance ratios (up to 0.2 ) the input torque needed to turn the augmented propeller is $10.0-12.0$ percent more than that of the baseline propeller. At advance ratios between 0.25 and 0.55 , the overall thrust coefficient of the augmented propeller increases by a factor of as much as $50 \%$ while the 


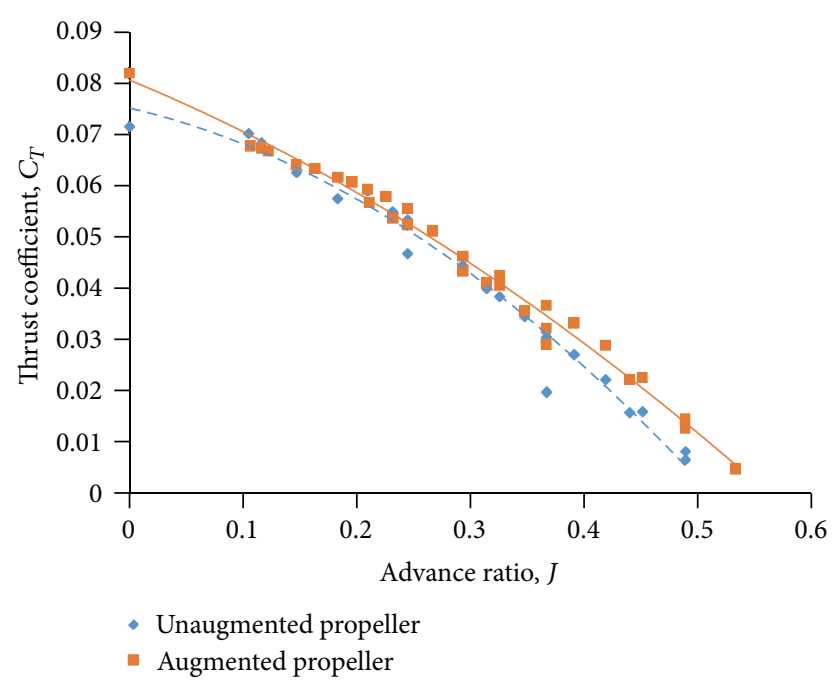

FIGURE 11: Output thrust coefficient comparison between augmented and unaugmented propeller experiments.

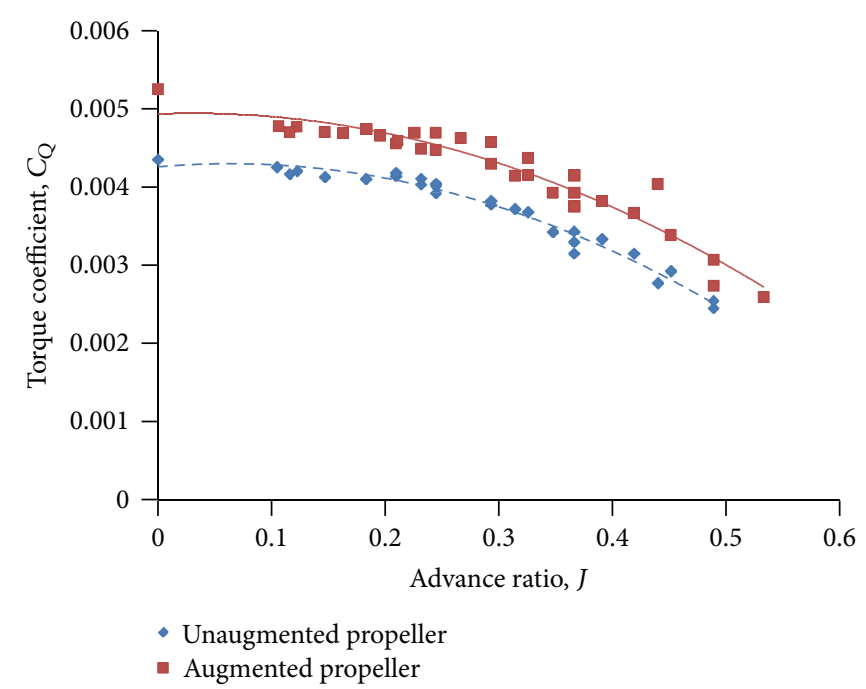

FIGURE 12: Input torque coefficient comparison between augmented and unaugmented propeller experimental data.

input torque coefficient increases by only 17 percent. This provides overall system efficiency benefit just from replacing the propeller on the aircraft. As the advance ratios begin to approach 0.60 , where the propeller ceases to make thrust, the input torque required to turn the propellers begins to equalize and shows little deviation from one another.

This portion of the experiment shows that the overall efficiency of the circulation control propeller increases due to the small increase input torque required to turn the propeller as well as the overall increase in output thrust measured over the medium range of values of advance ratios $(0.25$ to 0.5$)$. As the advance ratios climbed above 0.60 during experimentation, the overall efficiency ratings of the two tested propellers show equality. Noted, however, was data collected at values of advance ratios above unity, the thrust forces as measured began resulting in negative values, and thus began the section

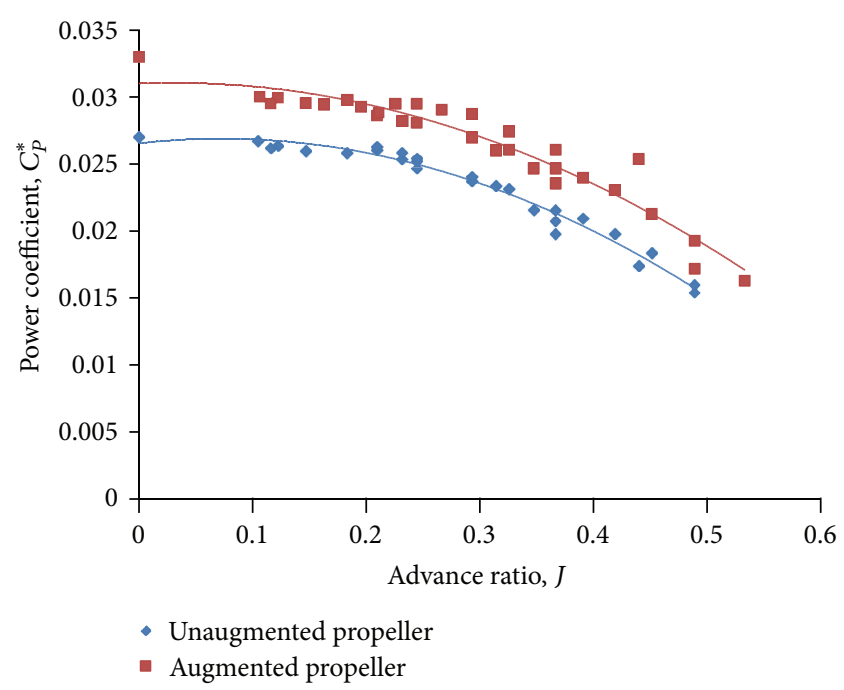

Figure 13: Power coefficient variation across advance ratio.

of the propeller flight envelope where the aerodynamic forces transitioned into a "windmill" type of loading.

This is when the propeller is so overloaded it begins taking power from the free-stream velocity, rather than energizing it. In Figure 13, the overall nondimensional power coefficient is shown with respect to advance ratio which shows a relatively consistent 8.0 to 10.0 percent difference in required power to run the propeller. This is expected as the power coefficient is based on the input torque needed to turn the propeller. The calculation of this data made overall efficiency of the propeller easier to calculate based on the ratios of input power and output thrust.

The data from the two experiments was reduced together, allowing for a piecewise trend study of the overall effect of circulation control on the prototype propeller from a coefficient and an efficiency standpoint. For the coefficient data, the information was reduced into Figures 11, 12, and 13 removing the repeated information between the two experiments via averaging and providing a cleaner overall plot of the data.

Similarly, the overall propeller efficiency, shown in Figure 14, with respect to experimental advance ratio was estimated across results gathered in the WPAFB wind tunnel environment. Together with the full spectrum of thrust coefficient $\left(C_{T}\right)$, power coefficient $\left(C_{P^{*}}\right)$ and torque coefficient $\left(C_{Q}\right)$ data, and overall efficiency $(\eta)$ prediction was tabulated for both the augmented and unaugmented propeller.

The use of the advance ratio of the propeller takes the output results of the experiment to a nondimensional value and allows for comparison of data between any number of different blade types, forward velocities, and thrust forces. As shown in Figure 14, the overall efficiency of the two studied propellers does not seem to change between the advance ratios of 0.0 and 0.30 , with the unaugmented propeller being just a fraction of a percent better overall.

However, at advance ratios between 0.31 and 0.55 , the experimental values of the augmented propeller show a better performance factor and higher efficiency ratings. Using an integration of the estimated curve of efficiency performance, 


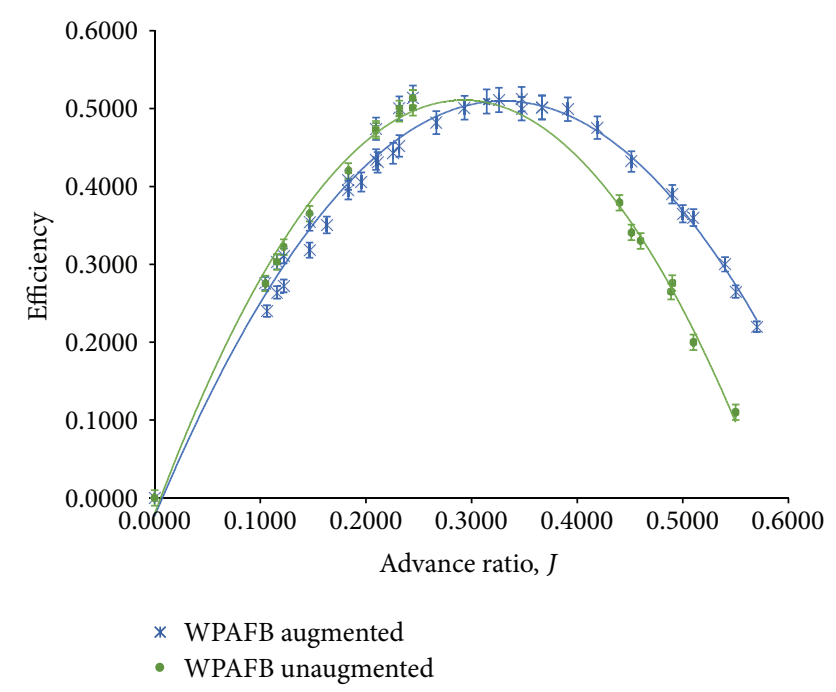

Figure 14: Propeller efficiency with respect to advance ratio and measurement error analysis.

the overall change in efficiency across the entire range of advance ratios is estimated to be 5.12 percent better using the CC propeller.

\section{Conclusions}

It is clear that this design utilizing passively energized circulation control requires a systems approach for future applications. Numerous studies have been conducted in the past on propellers including the use of active blowing slots to create large increases in thrust delivery. As with most active circulation control systems, use of the hardware, weight, and pumping penalties far outweighs the benefits for all but few unique applications. In contrast, and particularly regarding consumption of fossil fuel and environmental consciousness, any improvements even single digit improvements will provide value to the UAV and propeller-driven aircraft industry.

It has been shown that this passive technology can provide such a benefit. With the employment of a retrofitted passively pressurized circulation control propeller, the need for changing the existing hardware vital to the aircraft's design can be avoided. The use of this passive circulation control system avoids the need for excess weight additions, such as pumping systems, to control the augmented jet velocity.

This research indicates that the passively pressurized system applied to a propeller can provide a net increase in overall efficiency of the aircraft, 5.12 percent, and thus provide proof-of-concept for the application of the technology. This concept, currently envisioned for UAV applications, suggests a single digit percent increase in the overall flight range of the aircraft. Results also show that for application of a propeller to a UAV which flies at a specific advance ratio, say 0.45 , the overall efficiency of the propeller increases by 9.5 percent.

Although small by conventional circulation control application standards, this improvement could greatly increase the overall versatility of the aircraft and is particularly attractive because there is no need for additional hardware additions to the currently employed aircraft. It merely requires a retrofitted propeller to the already existing aircraft frame.

\section{Recommendations}

This research work looked specifically into the application of adding a passively controlled circulation plenum and ejection slot to improve overall range performance in UAV application. It stands to reason, through scaling techniques and Reynolds Number matching, that the application of this technology to larger propeller-driven aircraft would behave similarly, but future testing scenarios to prove this hypothesis will need to be scheduled. Further work into the rotational aspect of the plenum pumping forces and experimentation into tailoring the plenum to each application is crucial.

In addition to optimization of the pressurization plenum, the exit slot and inlet to the pressurization chamber should also be optimized based on the applications. The selection of the position along the radius and the jet exit dimensions will allow for optimization of the entire system, as well as making the exit area the limiting dimension of the system to provide consistent pressurization for the jet velocity. Both of these facets of the design are mainly dependent upon how the propeller is manufactured, and the smaller the model becomes, the harder it is to accommodate resilient materials for the construction.

In order to be able to study this effect a particle image velocimetry (PIV) wind tunnel study could be helpful in determining the actual output velocities and pressures of the circulation control plenum directly at the exit slot. Without a built-in way of measuring the output pressure of the plenum, the rotational aspect of the system makes data collecting difficult. Due to cost constraints of this particular experiment, no such study was feasible. Future experimental model considerations could possibly include a preexisting mounted hotwire anemometer or ultrasonic anemometer near and/or at the inlet and exit of the CC plenum in order to accurately determine the input and output velocities available during testing. Velocity and pressurization gages could also be useful within the plenum itself in order to read the maximum and minimum values in which the plenum can be pressurized during use. Due to the rotational nature of this experimental setup, the electronics used to measure velocities and pressures within the experimental system would also need to be able to transmit data wirelessly, or through a slip ring to avoid interference with the propeller.

Also, a possible area of interest is the higher rotational speed testing regimes of a propeller model. As this study was meant to show how the technology behaved, the high end speeds, subsequent higher tip Reynolds numbers, and fully turbulent flow characteristics could show interesting effects when transferred through the ranges of incompressible and compressible fluid behavior as well as sonic and transonic speed regimes. Again, the use of stronger modeling materials and testing equipment would need to be used in order to study these effects. Perhaps a larger scale testing scenario would also be beneficial for this type of experimentation. 


\section{Nomenclature}

AFRL: Air Force Research Lab

CC: $\quad$ Circulation control

$C_{\mathrm{Q}}: \quad$ Torque coefficient

$C_{T}: \quad$ Thrust coefficient

ESC: Electronic speed controller

$J: \quad$ Advance ratio

$\eta: \quad$ Efficiency

rpm: Rotations per minute

UAV: Unmanned aerial vehicle

WPAFB: Wright-Patterson Air Force Base

WVU: West Virginia University.

\section{Conflict of Interests}

The authors declare that there is no conflict of interests regarding the publication of this paper.

\section{References}

[1] R. A. Churchill, Coandă effectJet around a cylinder with an interacting adjacent surface [Ph.D. dissertation], Department of Aerospace Engineering, West Virginia University, Morgantown, WVa, USA, 1992.

[2] J. C. Ashworth, An experiment investigation of a circulation controlled shrouded propeller [M.S. thesis], Department of Mechanical and Aerospace Engineering, West Virginia University, Morgantown, WVa, 1977.

[3] M. E. Franke and J. K. Harvell, "Wind tunnel studies of circulation control elliptical airfoils," Tech. Rep. N88-17598, Air Force Institute of Technology, Wright-Patterson Air Force Base, Dayton, Oh, USA, 1987.

[4] J. Kweder, C. C. Panther, and J. E. Smith, "Applications of circulation control, yesterday and today," International Journal of Engineering, vol. 4, no. 5, 2010.

[5] E. O. Rogers and M. J. Donnelly, "Characteristics of a dualslotted circulation control wing of low aspect ratio intended for naval hydrodynamic applications," in Proceedings of the 42nd AIAA Aerospace Sciences Meeting and Exhibit, pp. 9995-10023, Reno, Nev, USA, January 2004.

[6] I. I. Angle and I. I. G. M, Aerodynamic benefits of nearsurface-actuated circulation control blowing slots for rotorcraft use [Ph.D. dissertation], Department of Aerospace Engineering, West Virginia University, Morgantown, WVa, 2008.

[7] I. I. Angle, I. I. G. M, W. W. Huebsch, J. C. Prucz, and J. E. Smith, "Circulation controlled, fixed-root helicopter concept," in Proceedings of the American Helicopter Society 62nd Annual Forum, Phoenix, AZ, USA, 2006.

[8] J. Abramson, Two-Dimensional Subsonic Wind Tunnel Evaluation of a 20-Percent-Thick Circulation Controlled Airfoil, David W. Taylor Naval Ship Research Center, Bathesda, Md, USA, 1975.

[9] J. Abramson, Characteristics of a Cambered Circulation Control Airfoil Having Both Upper and Lower Surface Trailing Edge Slots, Naval Surface Warfare Center-Carderock Division, Bathesda, Md, USA, 2004.

[10] R. J. Englar, "Two-dimensional subsonic wind tunnel tests of two 15-percent thick circulation control airfoils," David W. Taylor Naval Ship Research and Development Center Technical Note AL-211, Washington, DC, USA, 1971.
[11] R. J. Englar and R. M. Williams, Design of a Circulation Control Stern Plane for Submarine Applications, David W. Taylor Naval Ship Research and Development Center, Bethesda, Md, USA, 1971.

[12] R. J. Englar and R. M. Williams, "Test techniques for high lift, two-dimensional airfoils with boundary layer and circulation control for application to rotary wind aircraft," Canadian Aeronautics and Space Journal, vol. 19, no. 3, pp. 93-108, 1973.

[13] R. J. Englar, Subsonic Two-Dimensional Wind Tunnel Investigation of the High-Lift Capability of Circulation Control Wing Sections, David W. Taylor Naval Ship Research and Development Center, Bathesda, Md, USA, 1975.

[14] R. J. Englar, "Experimental investigation of the high velocity coandă wall jet applied to bluff trailing edge circulation control airfoils," Tech. Rep. 4708, David W. Taylor Naval Research and Development Center, 1975.

[15] R. J. Englar, Development of the A-6/Circulation Control Wing Flight Demonstrator Configuration, David W. Taylor Naval Ship Research and Development Center, Bathesda, Md, USA, 1979.

[16] R. J. Englar, J. H. Nichols, M. J. Harris, J. C. Eppel, and M. D. Shovlin, "Circulation control technology applied to propulsive high-lift systems," in Proceedings of the Society of Automotive Engineers, Aerospace Congress and Exposition, Long Beach, Calif, USA, 1984.

[17] R. J. Englar, "The application of circulation control pneumatic technology to powered-lift STOLaircraft," Tech. Rep. 872335, Advanced Flight Systems Department, Lockheed Aeronautical Systems Company, Marietta, Ga, USA, 1987.

[18] R. J. Englar, "Overview of circulation control pneumatic aerodynamics: blown force and moment augmentation and modification as applied primarily to fixed-wing aircraft," in Proceedings of the NASA/ONR Circulation Control Workshop, National Aeronautics and Space Administration, 2005.

[19] J. L. Loth, J. B. Fanucci, and S. C. Roberts, "Flight Performance of a Circulation Controlled STOL Aircraft," Journal of Aircraft, vol. 13, no. 3, 1976.

[20] J. L. Loth and M. Boasson, "Circulation controlled STOL wing optimization," Journal of Aircraft, vol. 21, no. 2, pp. 128-134, 1984.

[21] J. L. Loth and M. S. Funk, "Thrust Savings Limitations with Blown high-lift Wings," in Proceedings of the AIAA/AHS/ASEE Aircraft Design, Systems and Operations Meeting, American Institute of Aeronautics and Astronautics, St. Louis, Mo, USA, 1987.

[22] J. J. Bertin, Aerodynamics for Engineers, Prentice \& Hall, Upper Saddle River, NJ, USA, 2002.

[23] A. L. Braslow, "Aerodynamic evaluation of circulation control propellers," Contractor Report 165748, National Aeronautics and Space Administration (NASA) and The Bionetics Corporation, Hampton, Va, USA, 1981.

[24] J. Kweder, M. Clarke, and J. E. Smith, "Investigation into the feasibility of an augmented propeller design with the use of a passive circulation control system," in Proceedings of the International Mechanical Engineering Congress \& Exposition, American Society of Mechanical Engineers, Vancouver, Canada, November 2010.

[25] G. S. Harness, An experimental investigation of a circulation controlled cambered elliptical airfoil [M.S. thesis], Department of Aerospace Engineering, West Virginia University, Morgantown, WVa, USA, 1970. 
[26] D. J. Holt, Circulation controlled airfoil with pulsed flow [M.S. thesis], Department of Mechanical and Aerospace Engineering, West Virginia University, Morgantown, WVa, USA, 1972.

[27] R. J. Kind and D. J. Maul, "An experimental investigation of a low-speed circulation-controlled aerofoil," The Aeronautical Quarterly, vol. 19, 1968.

[28] C. J. Novak, K. C. Cornelius, and R. K. Roads, "Experimental investigations of the circular wall jet on a circulation control airfoil," in Proceedings of the 25th Aerospace Sciences Meeting, American Institute of Aeronautics and Astronautics, Reno, Nev, USA, 1987.

[29] N. J. Wood, "The aerodynamics of circulation control aerofoils," Tech. Rep. SU-JIAA TR-41, Stanford University, Stanford, Calif, USA, 1981.

[30] R. M. Williams, "Some aspects on rotor circulation control," in CAL/AVLABS 3rd Symposium of Rotary Wing and V/STOL Aircraft, Buffalo, NY, USA, 1969.

[31] J. Ottensoser, Two-Dimensional Subsonic Evaluation of a 15Percent Thick Circulation Control Airfoil with Slots at Leading and Trailing Edges, David W. Taylor Naval Ship Research and Development Center, Bethesda, Md, USA, 1974.

[32] E. H. Gibbs, Analysis of circulation controlled airfoils [Doctorate of Philosophy Dissertation], Department of Mechanical and Aerospace Engineering, West Virginia University, Morgantown, Wva, USA, 1975.

[33] Zinger, “Zinger Propeller," http://www.zingerpropeller.com. 

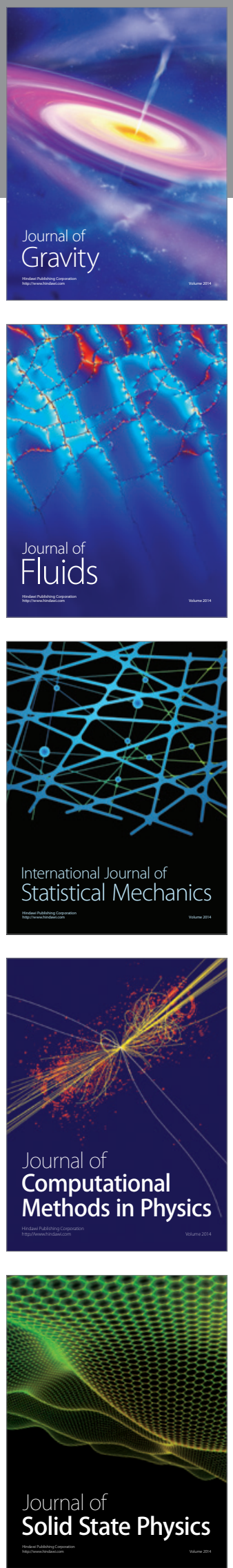

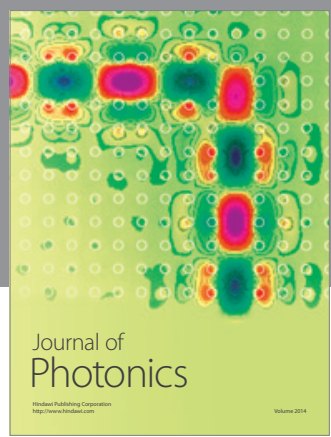

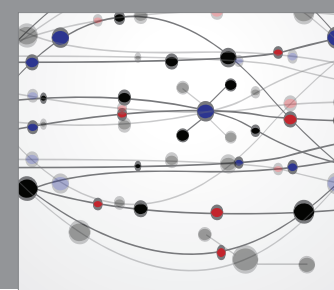

The Scientific World Journal

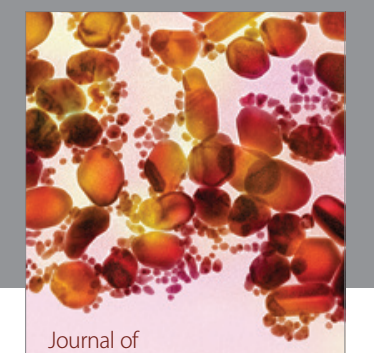

Soft Matter
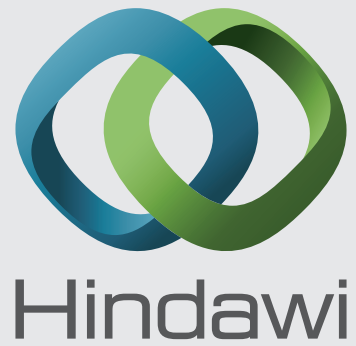

Submit your manuscripts at

http://www.hindawi.com
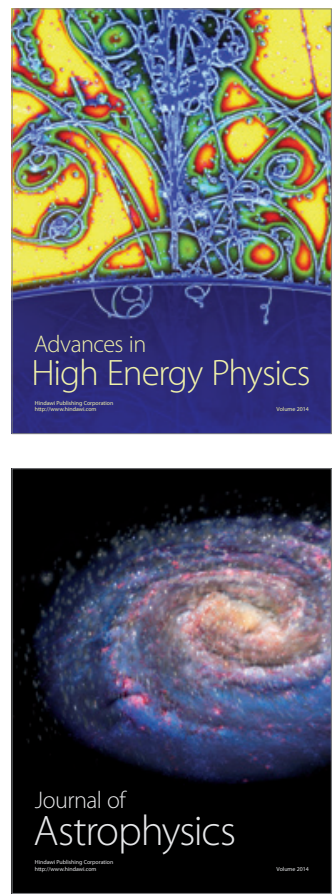
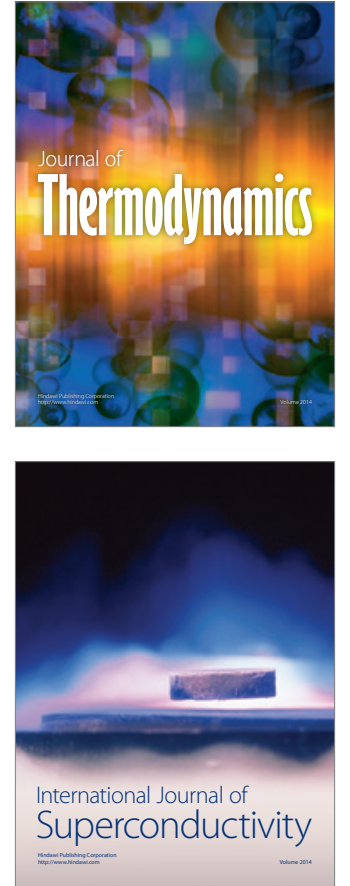
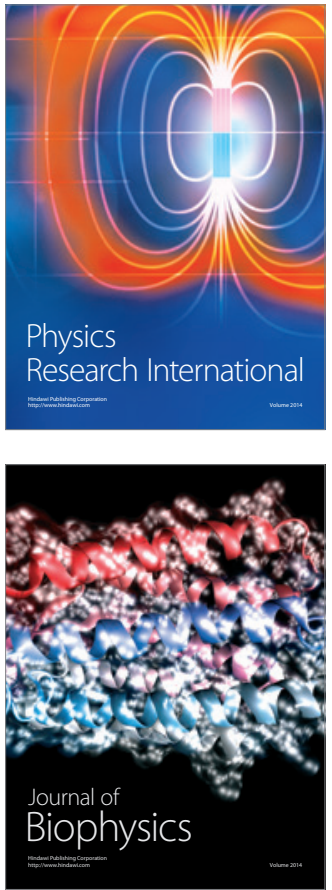
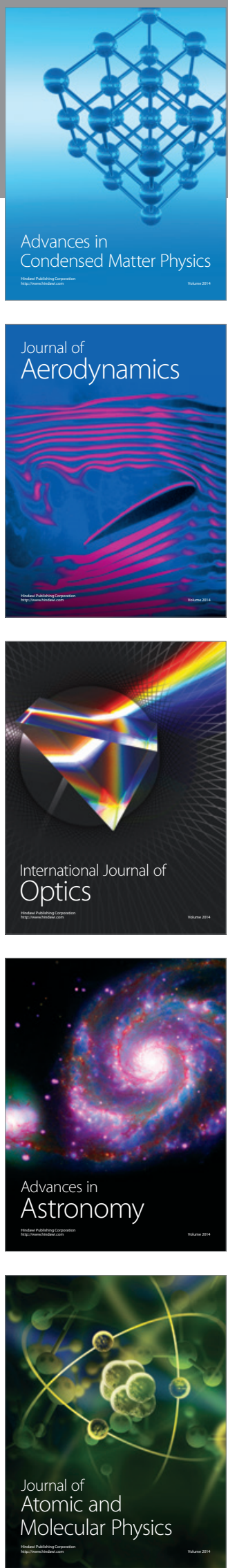